\title{
Perinatal and follow-up outcome study of fetal anomalies with multidisciplinary consultation
}

\author{
Genxia Li ${ }^{1}, *$ \\ $\mathrm{Na}$ Yang ${ }^{2, *}$ \\ Mingkun Xie' \\ Yajuan $\mathrm{Xu}{ }^{\prime}$ \\ Ning Han' \\ Qi Chen ${ }^{3}$ \\ Hezhou $\mathrm{Li}^{4}$ \\ Yueli Wu ${ }^{5}$ \\ Chunhua Cheng' \\ Yuhong Wang' \\ Man Zhou ${ }^{6}$ \\ Bo $\mathrm{Xia}^{6}$ \\ Shuhua Guo' \\ Shihong Cui' \\ 'Department of Obstetrics and \\ Gynecology, The Third Affiliated \\ Hospital of Zhengzhou University, \\ Zhengzhou, ${ }^{2}$ Department of \\ Obstetrics and Gynecology, The First \\ People's Hospital in Guangzhou, \\ Guangzhou, ${ }^{3}$ Department of Pediatric \\ Surgery, ${ }^{4}$ Department of Ultrasound, \\ ${ }^{5}$ Department of Genetics Laboratory, \\ The Third Affiliated Hospital of \\ Zhengzhou University, Zhengzhou, \\ China; ${ }^{6}$ Department of Genetics and \\ Biochemistry, Clemson University, \\ Clemson, SC, USA \\ *These authors contributed equally \\ to this work
}

This article was published in the following Dove Press journal:

Therapeutics and Clinical Risk Management

4 October 2017

Number of times this article has been viewed

Synopsis: The establishment of a multidisciplinary consultation system is necessary for the diagnosis of complicated fetal anomalies.

Purpose: We aimed to investigate the incidences of different types of fetal anomalies and the influence of multidisciplinary consultation on fetal prognosis.

Patients and methods: Multidisciplinary specialists include obstetricians, pediatricians, pediatric surgeons, and experts of ultrasound department and genetic counseling. Consultation was done if the fetal ultrasound examinations showed abnormality. Follow-up, assistance, and guidance for the fetus were achieved by phone calls.

Results: Ultrasound screening showed that the incidences of central nervous system anomaly and genitourinary anomaly were $25.80 \%(275 / 1,066)$ and $22.05 \%(235 / 1,066)$, respectively. The detection rates of fetal anomalies were $5.07 \%(54 / 1,066), 36.12 \%(385 / 1,066)$, and $58.82 \%$ $(627 / 1,066)$ in pregnant women with gestational age of $<20,20-28$, and $>28$ weeks, respectively. In addition, the fetal cerebral ventriculomegaly accounted for $40.73 \%$ of central nervous system malformation, while $71.43 \%$ cases with fetal cerebral ventriculomegaly were alleviated during the follow-up period. The proportion of hydronephrosis in genitourinary anomalies was $50.64 \%$, and the remission rate of hydronephrosis was $67.23 \%$ during the follow-up period.

Conclusion: The establishment of a multidisciplinary consultation system is necessary for the diagnosis of complicated fetal anomalies. The central nervous system anomaly and genitourinary anomaly are the most common fetal anomalies. In addition, the remission rates of cerebral ventriculomegaly and fetal hydronephrosis are high during the follow-up period.

Keywords: multidisciplinary consultation, fetal anomalies, pregnancy outcome

\section{Introduction}

Congenital fetal anomaly is recognized by single or multiple birth defects in the morphology of discernible organs or body, leading to a high infant mortality worldwide. ${ }^{1}$ Fetal anomaly not only increases the risk of infant death but also causes great pain to the family. ${ }^{1,2}$ Therefore, it is necessary to adopt timely and accurate diagnosis as well as appropriate intervention for congenital fetal anomaly.

In recent years, due to the rapid development in genetics, immunology, embryology, biochemistry progress, and epidemiology research studies, diagnosis of congenital fetal anomalies are significantly improved. Currently, the diagnosis of congenital fetal anomaly mainly depends on prenatal ultrasound screening and laboratory examination. ${ }^{1,3,4}$ However, the inspection range of laboratory examination is limited and it combines certain risk, for instance, the infection of puncture point, prenatal ultrasound screening is considered as one of the effective means of intervention for birth defect control. ${ }^{4}$ Ultrasound, as a non-invasive prenatal diagnosis technology, not only has a high detection rate of fetal anomaly but also can be repeatedly checked without effects on 
the pregnant woman and fetus. ${ }^{5}$ For the definite diagnosis of severe compound defects and deadly malformations, pregnant women are advised to terminate pregnancy by induced labor. ${ }^{5}$ However, some fetal anomalies are relatively complicated, and need the intervention of multidisciplinary knowledge, including genetics, neonatology, pediatrics, medical imaging, and obstetrics. ${ }^{6}$ Previous studies have focused on the multidisciplinary antenatal diagnosis and management, indicating the significance of multidisciplinary consultation in the diagnosis of congenital fetal anomaly. ${ }^{7-9}$ However, few studies have investigated the pregnancy outcomes of fetal anomalies with a large sample size after multidisciplinary consultation.

In the present study, we reviewed 1,066 pregnant women who received multidisciplinary consultation after the diagnosis of fetal anomalies and evaluated the pregnancy outcomes of different types of fetal anomalies during the follow-up period. We aimed to investigate the incidence of different types of fetal anomalies and the influence of multidisciplinary consultation on fetal prognosis.

\section{Materials and methods}

\section{Patients}

This retrospective study was approved by the Ethics Committee of the Third Affiliated Hospital of Zhenzhou University. A total of 11,051 pregnant women were diagnosed with fetal anomaly by ultrasonography examination between January 2010 and January 2013. Of these, 1,066 pregnant women who received multidisciplinary consultation were included in this study. Written informed consent was signed before each patient took part in the consultation for both the consultation and the use of the medical records for future research and publications. The patients who had received a suggestion of obvious fatal anomaly by ultrasonic diagnosis but refused to participate in multidisciplinary consultation were excluded. The pregnancy time of patients (aged 19-46 years) ranged from 11 to 41 weeks.

\section{Diagnostic method}

A maternal-fetal medicine specialist team comprises multidisciplinary specialists, including obstetrics, pediatric internal medicine, pediatric surgery, ultrasound department, and genetic counseling laboratory. First, pregnant women who were diagnosed with fetal anomalies by ultrasonography examination were consulted in the outpatient department. If it was controversial on whether the fetus should be kept due to clinical cognitive deficiency, pregnant women were advised to participate in multidisciplinary consultation. Meanwhile, the baseline data of pregnant women, including maternal age, gestational age, gravidity, color ultrasound result, abnormal pregnancy history, address, and phone number, were recorded in detail. Then, the individual patient data were provided to every expert prior to experts' consultation. Prenatal diagnosis was carried out according to Practical Prenatal Diagnosis. ${ }^{10}$ As a result, the suggestion of consultation was presented in a written form. The patients who participated in multidisciplinary consultation were followed up for 1-3 years.

\section{Results}

\section{Ultrasound screening outcomes}

Ultrasound screening showed that among 1,066 pregnant women, various types of fetal anomaly were included, namely central nervous system anomaly $(275 / 1,066,25.80 \%)$, genitourinary anomaly $(235 / 1,066,22.05 \%)$, cardiac vascular anomaly $(100 / 1,066,9.38 \%)$, respiratory anomaly (29/1,066, 2.72\%), gastrointestinal anomaly (95/1,066, $8.91 \%)$, facial deformity $(4 / 1,066,0.38 \%)$, musculoskeletal anomaly $(50 / 1,066,4.69 \%)$, ascites and pleural effusion $(31 / 1,066,2.91 \%)$, cystic hygroma $(26 / 1,066,2.44 \%)$, teratoma $(9 / 1,066,0.84 \%)$, multiple malformations $(46 / 1,066$, $4.32 \%)$, and other malformations $(166 / 1,066,15.57 \%)$. The detection rates of fetal anomalies were 5.07\% $(54 / 1,066)$, $36.12 \%(385 / 1,066)$, and $58.82 \%(627 / 1,066)$ in pregnant women with gestational age of $<20,20-28$, and $>28$ weeks, respectively (Table 1). In addition, 316 (29.64\%), 398 (37.34\%), 233 (21.86\%), and 119 (11.16\%) fetal anomalies, respectively, were detected in pregnant women aged $<25$, $25-30,30-35$, and $>35$ years.

\section{Multidisciplinary consultation and follow- up outcomes}

After multidisciplinary consultation, the suggestions including induced labor, continual observation, chromosome

Table I The distribution of fetal anomalies by ultrasonic diagnosis in different gestational ages

\begin{tabular}{lllll}
\hline Types of fetal anomaly & \multicolumn{2}{l}{ Gestational age } & \multirow{2}{*}{ Total } \\
\cline { 2 - 4 } & $\begin{array}{l}<\mathbf{2 0} \\
\text { weeks }\end{array}$ & $\begin{array}{l}\mathbf{2 0 - 2 8} \\
\text { weeks }\end{array}$ & $\begin{array}{l}>\mathbf{2 8} \\
\text { weeks }\end{array}$ \\
\hline Central nervous system anomaly & 9 & 76 & 190 & 275 \\
Genitourinary anomaly & 3 & 91 & 141 & 235 \\
Cardiac vascular anomaly & 3 & 40 & 57 & 100 \\
Respiratory anomaly & 0 & 20 & 9 & 29 \\
Gastrointestinal anomaly & 2 & 40 & 53 & 95 \\
Facial deformity & 0 & 1 & 3 & 4 \\
Musculoskeletal anomaly & 2 & 12 & 36 & 50 \\
Ascites and pleural effusion & 2 & 10 & 19 & 31 \\
Cystic hygroma & 12 & 7 & 7 & 26 \\
Teratoma & 0 & 6 & 3 & 9 \\
Multiple malformations & 2 & 20 & 24 & 46 \\
Other & 19 & 62 & 85 & 166 \\
Total & 54 & 385 & 627 & 1,066 \\
\hline
\end{tabular}


Table 2 Pregnancy outcomes in 1,066 fetal anomalies

\begin{tabular}{|c|c|c|c|c|c|}
\hline \multirow[t]{2}{*}{ Types of fetal anomaly } & \multirow[t]{2}{*}{ Number } & \multicolumn{4}{|c|}{ Pregnancy outcomes } \\
\hline & & $\begin{array}{l}\text { No } \\
\text { abnormalities }\end{array}$ & $\begin{array}{l}\text { Induced } \\
\text { labor }\end{array}$ & $\begin{array}{l}\text { Deformity } \\
\text { correction surgery }\end{array}$ & $\begin{array}{l}\text { Lost to } \\
\text { follow-up }\end{array}$ \\
\hline Central nervous system anomaly & 275 & 182 & 64 & 5 & 24 \\
\hline Genitourinary anomaly & 235 & 128 & 78 & 21 & 8 \\
\hline Cardiac vascular anomaly & 100 & 51 & 41 & $\mathrm{I}$ & 7 \\
\hline Respiratory anomaly & 29 & 16 & 11 & 0 & 2 \\
\hline Gastrointestinal anomaly & 95 & 36 & 39 & 14 & 6 \\
\hline Facial deformity & 4 & 0 & 3 & 1 & 0 \\
\hline Musculoskeletal anomaly & 50 & 28 & 13 & 6 & 3 \\
\hline Ascites and pleural effusion & 31 & 3 & 25 & 2 & 1 \\
\hline Cystic hygroma & 26 & 6 & 18 & 1 & I \\
\hline Teratoma & 9 & 1 & 7 & 7 & 1 \\
\hline Multiple malformations & 46 & 3 & 39 & 1 & 3 \\
\hline Other & 166 & 104 & 30 & 6 & 26 \\
\hline
\end{tabular}

examination, and operative treatment were provided. As a result, the decision of termination or continuation of a pregnancy was made by the pregnant women and their families. The follow-up outcomes of different types of fetal anomalies are shown in Table 2. In 275 cases with central nervous system anomaly, 182 cases had no abnormalities, 64 cases chose induced labor, five cases underwent the corresponding deformity correction surgery, and 24 cases were lost to follow-up. In addition, the fetal cerebral ventriculomegaly accounted for $40.73 \%$ of central nervous system malformation, while $71.43 \%$ cases with fetal cerebral ventriculomegaly were alleviated before or after birth. In 235 cases with genitourinary anomaly, 128 cases had no abnormalities, 78 cases chose induced labor, 21 cases underwent the corresponding deformity correction surgery, and eight cases were lost to follow-up. Among these cases with genitourinary anomaly, hydronephrosis accounted for $50.64 \%$, and the remission rate of hydronephrosis was $67.23 \%$ before or after birth.

\section{Discussion}

Prenatal ultrasound screening is an important method for the diagnosis of congenital fetal anomaly. In order to timely and accurately expose the development condition of fetal organs, the best gestational age for the screening of fetal anomaly should be cautiously chosen. ${ }^{11}$ Previous study had shown that ultrasound examination at different gestational ages influenced the detection rate of fetal anomaly. ${ }^{12}$ In our study, $41.19 \%$ fetal anomaly was diagnosed before the gestational age of 28 weeks. If the screening of fetal anomaly starts after 28 weeks, $41.19 \%$ fetal anomaly would be misdiagnosed. But if the screening starts between 20 to 28 weeks, the misdiagnosed rate would be $5.07 \%$, which is significantly reduced. These results suggested that birth defect surveillance should be initiated before 28 gestational weeks. This might explain that 1) fetal anatomic structure has been formed and shown by ultrasound; 2) fetal size and amniotic fluid were moderate, which was beneficial to the observation of ultrasound images; 3) a comprehensive inspection of the fetus from multiple angles and directions could be performed due to the large range of fetal movement, thereby most of the fetal anomalies could be displayed. Therefore, mid pregnancy may be more suitable for the screening of fetal anomalies. ${ }^{13}$

For patients with complicated conditions, multidisciplinary consultation was recommended. The establishment of a multidisciplinary consultation system could not only promote the development of prenatal ultrasound screening but also improve the accuracy of ultrasound diagnosis and avoid the occurrence of over diagnosis, misdiagnosis, or missed diagnosis. ${ }^{14}$ Multidisciplinary consultation could put forward comprehensive and professional information for the patients, including the types of fetal anomalies, fetal prognosis, and the success rate of fetal surgery after birth, ${ }^{15-17}$ thereby relieving the mental burden of pregnant women and their families, as well as providing pregnancy, intrapartum, delivery, and postnatal guidance for pregnant women who decide to continue the pregnancy. In addition, further follow-up could comprehensively explain the occurrence and development of fetal anomalies and then improve the management of prenatal diagnosis and consultation. ${ }^{18}$ Previous studies revealed that $41 \%$ of fetuses survived through the multidisciplinary consultation and obtained effective diagnosis and treatment after birth. ${ }^{19,20}$

Various types of fetal anomalies have been reported. More attention has been focused on central nervous system anomalies due to their high incidence and complicated conditions. Central nervous system anomalies also include fetal cerebral ventriculomegaly, choroid plexus cysts, callosal agenesis, Dandy-Walker syndrome, and spina bifida. In our study, fetal 
ventricular diameter returned to normal in $71.43 \%$ of fetuses who had mild fetal cerebral ventriculomegaly without other structural and chromosomal abnormalities. Thus, we speculated that mild fetal cerebral ventriculomegaly might have less clinical significance, and it might be caused by the temporary disorder of lateral ventricle. Even so, pregnant women should be subject to periodic reexaminations. However, for patients with severe fetal cerebral ventriculomegaly, induced labor was recommended due to poor prognosis. ${ }^{21}$ Ultrasound examinations in the diagnosis of congenital heart diseases have higher technical requirements for instruments and operators, which limit the accuracy of diagnosis. In order to further improve the accuracy of diagnosis, operators need to accumulate experience and improve their performance in the work. Our study also found that genitourinary anomalies had a high incidence (22.05\%), in which $50.64 \%$ of fetuses were diagnosed with hydronephrosis. Previous study showed that $88 \%$ of antenatal hydronephrosis was relieved during pregnancy. ${ }^{22}$ Similarly, our study also demonstrated a remission rate of $67.23 \%$ in fetuses with hydronephrosis. These results indicate that fetal hydronephrosis should not be considered as an indication of induced labor. Accurate prediction for prognosis and timely fetal intervention might avoid unnecessary termination of pregnancy. In addition, our study reported that $80.6 \%(25 / 31)$ of patients with ascites and pleural effusion chose induced labor. Fetal massive ascites may lead to abdominal bulge which increases the risk of obstructive dystocia. From this point of view, early termination of pregnancy was recommended. Cystic hygroma was relatively rare, and accounted for $2 \%-3 \%$ of fetal anomalies. In this study, only one patient underwent deformity correction surgery and $69.23 \%$ (18/26) of patients chose induced labor. The prognosis of cystic hygroma was poor. Patients with normal chromosome karyotype were also at high risk of aborting the fetus; if they continued to the third trimester of pregnancy, the risks of cardiac and musculoskeletal anomalies might increase. Although multidisciplinary consultation was carried out, many patients with fetuses who could be properly treated still chose induced labor in this study. The reasons mainly included ethical considerations, expensive treatments, social pressure, and a skeptical attitude toward long-term efficacy.

\section{Conclusion}

The establishment of a multidisciplinary consultation system is necessary for the diagnosis of complicated fetal anomalies. The central nervous system anomaly and genitourinary anomaly are the most common fetal anomalies. In addition, the remission rates of cerebral ventriculomegaly and hydronephrosis fetal anomaly are high during the follow-up period.

\section{Acknowledgments}

We would like to thank Fuyun Liu, Lihua Zhang, Shunyang Fan, Yan Huang, and Juan Wu of the Department of Pediatric Surgery; Jie Li and Yun Liu of the Department of Pediatric Ultrasound; Xiao Kong of the Department of Obstetrics and Gynecology; and Linlin Zhang of the Department of Genetics Laboratory, The Third Affiliated Hospital of Zhengzhou University, Zhengzhou, China 450052, for their kind help.

\section{Author contributions}

All the authors were involved in design, read and approved the final manuscript, were involved in acquisition, analysis, and interpretation of data, drafting, and revising the manuscript, approved the final version of the manuscript, and agreed to be accountable for all aspects of the work in ensuring that questions related to the accuracy or integrity of any part of the work were appropriately investigated and resolved.

\section{Disclosure}

The authors report no conflicts of interest in this work.

\section{References}

1. Corsello G, Giuffrè M. Congenital malformations. J Matern Fetal Neonatal Med. 2012;25:25-29.

2. Lee K-S, Khoshnood B, Chen L, Wall SN, Cromie WJ, Mittendorf RL. Infant mortality from congenital malformations in the united states, 1970-1997. Obstet Gynecol. 2001;98:620-627

3. UK National Screening Committee. Fetal anomaly screening programme - screening for Down's syndrome: UK NSC policy recommendations 2007-2010: model of best practice. Department of Health Policy Guideline No. DH_084731; 2008.

4. Pathak S, Lees C. Ultrasound structural fetal anomaly screening: an update. Arch Dis Child Fetal Neonatal Ed. 2009;94:F384-F390.

5. Paladini D, Volpe P. Ultrasound of Congenital Fetal Anomalies: Differential Diagnosis and Prognostic Indicators. 2nd Ed. Florida: CRC Press; 2014:1-29.

6. Bianchi D, Crombleholme T, D'Alton M, Malone F. Fetology: Diagnosis and Management of the Fetal Patient: Diagnosis and Management of the Fetal Patient. 2nd ed. New York: McGraw Hill Professional; 2010:63-67.

7. Kilby MD, Pretlove SJ, Russell ARB. Multidisciplinary palliative care in unborn and newborn babies. BMJ. 2011;342:d1808.

8. Aite L, Trucchi A, Nahom A, Spina V, Bilancioni E, Bagolan P. Multidisciplinary management of fetal surgical anomalies: the impact on maternal anxiety. Eur J Pediatr Surg. 2002;12:90-94.

9. Luks F, Carr S, Feit L, Rubin L. Experience with a multidisciplinary antenatal diagnosis and management model in fetal medicine. J Matern Fetal Neonatal Med. 2003;14:333-337.

10. Bian X, Wu L, Jiang Y. Practical Prenatal Diagnosis. People's Medical Publishing House (NC); 2008:496-503. Chinese.

11. Campbell S. Diagnosis of fetal abnormalities by ultrasound. In: Milunsky A, editor. Genetic Disorders and the Fetus. Springer; 1979: 431-467. 
12. Romosan G, Henriksson E, Rylander A, Valentin L. Diagnostic performance of routine ultrasound screening for fetal abnormalities in an unselected swedish population in 2000-2005. Ultrasound Obstet Gynecol. 2009;34:526-533.

13. Salomon L, Alfirevic Z, Berghella V, et al. Practice guidelines for performance of the routine mid-trimester fetal ultrasound scan. Ultrasound Obstet Gynecol. 2011;37:116-126.

14. Bijma HH, Schoonderwaldt EM, van der Heide A, Wildschut HI, van der Maas PJ, Wladimiroff JW. Ultrasound diagnosis of fetal anomalies: an analysis of perinatal management of 318 consecutive pregnancies in a multidisciplinary setting. Prenat Diagn. 2004;24:890-895.

15. Aite L, Trucchi A, Nahom A, Zaccara A, La Sala E, Bagolan P. Antenatal diagnosis of surgically correctable anomalies: effects of repeated consultations on parental anxiety. J Perinatol. 2003;23:652-654.

16. Raboei E. The role of the pediatric surgeon in the perinatal multidisciplinary team. Eur J Pediatr Surg. 2008;18:313.
17. Colby CE, Carey WA, Blumenfeld YJ, Hintz SR. Infants with prenatally diagnosed anomalies: Special approaches to preparation and resuscitation. Clin Perinatol. 2012;39:871-887.

18. Farel AM, Meyer RE, Hicken M, Edmonds LD. Registry to referral: using birth defects registries to refer infants and toddlers for early intervention services. Birth Defects Res A Clin Mol Teratol. 2003;67: $647-650$.

19. Tsao K, Wei B, Ball R, et al. Fetal intervention may benefit fetuses with severe right-sided cdh. Am J Obstet Gynecol. 2003;189:S214.

20. Mohaupt S, Sharma K. Forensic implications and medical-legal dilemmas of maternal versus fetal rights. J Forensic Sci. 1998;43:985-992.

21. Breeze AC, Alexander P, Murdoch EM, Missfelder-Lobos HH, Hackett GA, Lees CC. Obstetric and neonatal outcomes in severe fetal ventriculomegaly. Prenat Diagn. 2007;27:124-129.

22. Liu DB, Armstrong WR, Maizels M. Hydronephrosis: prenatal and postnatal evaluation and management. Clin Perinatol. 2014;41:661-678.
Therapeutics and Clinical Risk Management

\section{Publish your work in this journal}

Therapeutics and Clinical Risk Management is an international, peerreviewed journal of clinical therapeutics and risk management, focusing on concise rapid reporting of clinical studies in all therapeutic areas, outcomes, safety, and programs for the effective, safe, and sustained use of medicines. This journal is indexed on PubMed Central, CAS,

\section{Dovepress}

EMBase, Scopus and the Elsevier Bibliographic databases. The manuscript management system is completely online and includes a very quick and fair peer-review system, which is all easy to use. Visit http://www.dovepress.com/testimonials.php to read real quotes from published authors.

Submit your manuscript here: http://www.dovepress.com/therapeutics-and-clinical-risk-management-journal 